\title{
Route Optimization Tool (RoOT) for distribution of vaccines
}

\section{and health products [version 1; peer review: 3 approved with}

\section{reservations]}

\author{
Zelda B. Zabinsky (iD), Mariam Zameer (iD2, Larissa P.G. Petroianu(iD), \\ Mamiza M. Muteia ${ }^{3}$, Aida L. Coelho 3 \\ ${ }^{1}$ Dept. of Industrial \& Systems Engineering, University of Washington, Seattle, Seattle, WA, 98195, USA \\ 2VillageReach, Seattle, WA, USA \\ ${ }^{3}$ VillageReach, Maputo, Mozambique
}

\section{V1 First published: 01 Mar 2021, 5:34 \\ https://doi.org/10.12688/gatesopenres.13219.1}

Latest published: 15 Nov 2021, 5:34

https://doi.org/10.12688/gatesopenres.13219.2

\begin{abstract}
Delivery of health products from provinces or districts to health facilities, including temperature-sensitive vaccines, is one of the most effective interventions to ensure availability of supplies and save lives in low- and middle-income countries. Currently, routes are hand drawn by logisticians that are adjusted based on vehicle availability and quantity of products. Easy-to-use supply chain tools are needed that planners can use in real-time to create or adjust routes for available vehicles and road conditions. Efficient and optimized distribution is even more critical with the COVID-19 vaccine distribution.
\end{abstract}

We develop a Route Optimization Tool (RoOT) using a variant of a Vehicle Routing and Scheduling Algorithm (VeRSA) that is coded in Python, but reads and writes Excel files to make data input and using outputs easier. The tool takes into account cold chain distribution, is easy-to-use, and provides routes quickly within two minutes. RoOT can be used for routine operations or in emergency situations, such as delivery of new COVID-19 vaccine. The tool has a user-centric design with easy dropdown menus and the ability to optimize on time, risk, or combination of both.

Training of logisticians in Mozambique indicate that RoOT is easy to use and provides a tool to improve planning and efficient distribution of health products, especially vaccines. We illustrate using RoOT in an emergency situation, such as a cyclone.

RoOT is an open-source tool for optimal routing of health products. It provides optimized routes faster than most commercial software, and is tailored to meet the needs of government stakeholders. Currently,

\section{Open Peer Review}

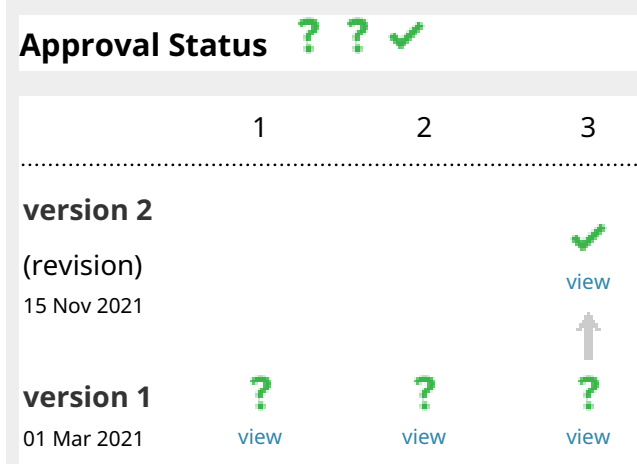

1. Hua Ni, USAID GHSC-PSM, Arlington, USA IBM GBS, Falls Church, USA

2. Ryan McWhorter, UNICEF, Copenhagen, Denmark

3. Andrew Inglis, USAID Global Health Supply Chain Programme, Procurement and Supply Management, International Business Machines, Arlington, USA Any reports and responses or comments on the article can be found at the end of the article. 
RoOT does not allow multi-day routes, and is designed for trips that can be completed within twenty-four hours. Areas for future development include multi-day routing and integration with mapping software to facilitate distance calculations and visualization of routes.

\section{Keywords}

Supply chain distribution, vaccines, cold chain, medical supplies, health products, vehicle routing, computational modeling, optimization, direct delivery, system design, risk, transit time, COVID19 , route optimization, system design, light-touch tools, optimized routing

\section{Corresponding authors: Zelda B. Zabinsky (zelda@uw.edu), Mariam Zameer (mariam.zameer@villagereach.org)}

Author roles: Zabinsky ZB: Conceptualization, Formal Analysis, Investigation, Methodology, Project Administration, Software, Supervision, Validation, Writing - Original Draft Preparation, Writing - Review \& Editing; Zameer M: Conceptualization, Funding Acquisition, Methodology, Project Administration, Resources, Supervision, Validation, Visualization, Writing - Original Draft Preparation, Writing - Review \& Editing; Petroianu LPG: Conceptualization, Data Curation, Formal Analysis, Investigation, Methodology, Software, Validation, Writing - Review \& Editing; Muteia MM: Formal Analysis, Investigation, Methodology, Validation; Coelho AL:

Conceptualization, Investigation, Methodology, Project Administration, Supervision, Validation

Competing interests: No competing interests were disclosed.

Grant information: The development of the Route Optimization Tool and this paper were possible with generous funding from the Bill \& Melinda Gates Foundation (OPP1195513).

The funders had no role in study design, data collection and analysis, decision to publish, or preparation of the manuscript.

Copyright: @ 2021 Zabinsky ZB et al. This is an open access article distributed under the terms of the Creative Commons Attribution License, which permits unrestricted use, distribution, and reproduction in any medium, provided the original work is properly cited.

How to cite this article: Zabinsky ZB, Zameer M, Petroianu LPG et al. Route Optimization Tool (RoOT) for distribution of vaccines and health products [version 1; peer review: 3 approved with reservations] Gates Open Research 2021, 5:34 https://doi.org/10.12688/gatesopenres.13219.1

First published: 01 Mar 2021, 5:34 https://doi.org/10.12688/gatesopenres.13219.1 


\section{Introduction}

Vaccines save millions of lives every year and save billions of dollars by reducing health care costs and preventing lost productivity $^{1}$, yielding an estimated 10 - to 25 -fold return on investment $^{2}$. Despite their effectiveness, global vaccination coverage has plateaued at $85 \%$ since 2010 and, in 2017, an estimated 20 million children lacked access to routine vaccination services-approximately $60 \%$ of whom lived in resourceconstrained countries ${ }^{3}$. One reason for stagnating coverage rates is inefficiencies in the immunization supply chain, which is increasingly challenged by population growth, new vaccine introductions, currency and policy fluctuations, and the introduction of new technologies and supply chain practices ${ }^{4}$. This is even more critical today, with the COVID-19 pandemic and the efficient distribution of the COVID-19 vaccine. Many governments and stakeholders looked to a COVID-19 vaccine when the pandemic hit. Now that the vaccine doses are arriving in low and middle income countries, it is important to plan for the efficient and optimized distribution.

Direct delivery of health products to health facilities, by districts or provinces, is one of the most effective interventions to improve product availability and reduce risk to vaccines. This is not only cost effective but gives health workers more time to provide services, and improve coverage, that would instead be spent traveling to pick up health products. Based on VillageReach's experience leading supply chain system design efforts using modeling tools in the Democratic Republic of the Congo, Mozambique, Pakistan, and $\mathrm{Zambia}^{5-7}$, direct delivery reduces stockouts, and contributes to improving equity. Additionally, health products, especially vaccines, are most at risk of temperature excursions during transit ${ }^{8-10}$; having products packed well and delivered efficiently to health facilities, reduces risk to products and maintains their potency. This is important for all vaccines, but especially so for COVID-19 vaccines due to limited supply, high demand, and the special ultra cold chain requirements for some vaccines.

For direct delivery, one of the most important decisions made by governments is effective routing that delivers products safely and quickly. Currently, routes are hand drawn by logisticians, and are not optimized for transit time or road conditions to improve availability and maintain vaccine potency. There is no tool available to allow logisticians to adjust plans quickly when the vehicle availability or situation changes, such as when a vehicle breaks down or a road is impassable due to flooding. Direct delivery distribution depends on vehicle availability, which often varies month to month, as well as the capacity of the vehicle for delivery. There are currently no supply chain tools and methods that logisticians can use in real-time to easily decide which vehicles to use for specific routes, and to quickly calculate if they can carry the required product volumes.

In 2019, Mozambique experienced Cyclone Idai, which devastated many health facilities across the country. Supply chains were disrupted leading to stockouts and unavailability of health products. Hence, an approach was needed to adjust supply chains to account for the road infrastructure that was destroyed, making some areas completely inaccessible, as well as changes to storage locations as some facilities were damaged. Additionally, make-shift facilities were set up in other areas to serve communities. Even for health facilities whose physical infrastructure was not impacted, their ability to maintain cold storage for vaccines was affected with disruptions in electricity in addition to the increasing numbers of people they were serving. This called for a shift in design of the supply chain system, and highlighted the need for a quick and easy way for logisticians to distribute health products where they were needed the most.

Based on our experience, we recognize the need for a new tool that can be used by governments and organizations who do not have the time, resources, ability, willingness, or political capital to conduct extensive optimization or simulation modeling that can sometimes take days to run, but will benefit from a fast and easy-to-use tool that provides results in minutes. Hence, we designed the Route Optimization Tool (RoOT), keeping in mind delivery of health products in routine and emergency settings, as well as the time and skills of government users.

\section{Landscaping of existing methods and tool}

Before developing RoOT, we did a literature review of the existing tools and methods available for optimizing distribution of health products based on minimizing risk of spoilage of health products. While there is extensive literature on the importance of transportation for health supply chains, infrastructure risks and financial systems are rarely addressed, and these are usually responsible for most of the network disruptions ${ }^{11}$. Often, the routing decision is based on the shortest distance, as it presumably reduces cost and leads to faster delivery. However, other risk factors, such as road failure from flooding, road sink, or bridge collapse, could make a recommended route infeasible ${ }^{12,13}$.

One option for optimizing routes is to incorporate the risk of road and infrastructure failures into the primary objective, instead of solely minimizing transit time or distance. Penalty parameters can be used as a way to incorporate the probability of road failure into an objective function, thus enabling the optimal routes to avoid unreliable roads, as in Hamedi et al. ${ }^{13}$ Studies show that using a minimum risk approach identifies routes that avoid critical roads and thus decrease risk ${ }^{14}$.

While analyzing risks for routing delivery of health products is not common ${ }^{11}$, risk is often used as the main objective when transporting hazardous materials ${ }^{15,16}$. Risk of spilling hazardous materials is addressed with the probability of accidents due to speed, road conditions, and busy intersections ${ }^{17}$. Accident rates are also assessed due to the time of day, weather conditions, and type of road $^{16,18}$. Using risk minimization, routes that avoid these dangers are preferred, even if there is an increase in travel time, as they ensure safe transport and delivery of materials.

In redesigning the supply chain for distribution of health products including vaccines and temperature sensitive products, we investigated different optimization tools that are available, including tools that perform inventory optimization, network optimization (minimize cost or distance) or route optimization. Since one of the main contributors to waste and 
spoilage of vaccines and temperature sensitive products is not maintaining effective cold chain during transport, we sought optimization tools that capture risk as well as transit time ${ }^{19}$. However, most decision support systems for logistics focus on inventory control and network optimization, and are not easily adapted to balance risk with transit time for route optimization $^{20}$.

During the landscaping analysis, we identified 18 vehicle routing software packages and 15 supply chain software packages that could be used in our context ${ }^{21}$. Most of the routing software used in commercial logistics focuses on distribution efficiency to minimize cost and time, and does not explicitly include risk as an objective. A user cannot easily modify these tools to tailor the objective functions and constraints for health products. Additionally, commercially available tools are costly, require special installation and training, may need to run for several hours to provide a solution, and are not easy-to-use or "light".

We narrowed down the 15 identified supply chain logistics software to two that had capabilities for optimizing routes: LLamasoft - Supply Chain Guru ${ }^{\circledR}$ Cloud-Based Supply Chain Design Software, and Global Logistic Competence (GLC) $)^{22,23}$. Our prior experience with using these tools was that they were complex to use, costly, and required advanced skills. Also, they require detailed data that is often not readily available in low- and middle-income countries (LMICs), such as for Mozambique.

The landscaping analysis identifies a clear need for a light-tool that can be used easily by a variety of stakeholders, without the need for advanced user skills or significant financial investment. There is also a need to tailor a software tool to represent considerations of risk of spoilage of health products.

\section{Methods}

\section{Model description}

The optimization model in RoOT is a variation of a vehicle routing optimization problem $^{24}$ that is tailored to address the needs of a cold chain distribution of temperature sensitive health products (such as vaccines) and ambient temperature health products (such as syringes or medicines). RoOT is designed to be easy to use, and is based in Microsoft Excel since it is a software most users in governments and local organizations working on supply chains are familiar with. VillageReach's experience in supporting government users in Mozambique was leveraged to ensure the optimization model could address common supply chain questions as summarized in Box 1 .

The input data for RoOT has seven sheets in Microsoft Excel:

1. Parameters: includes basic parameters and option to select optimization function

2. Products: list of all health products and temperature for storage

3. Center Capacities: cold and ambient storage capacities

\section{Box 1. Modeling support needed by government users}

RoOT is designed to meet the modeling needs of government users, based on questions that government stakeholders are typically interested in modeling:

- How does changing the resupply frequency, impact the quantity delivered at each distribution?

- What adjustments are needed when a new vaccine or health product is added to a distribution route?

- What vehicle is needed and routes adjusted if a new health facility is added to distribution route?

- What is the transport cost for each distribution route option?

- What changes in routes are needed if a road is unavailable or if the road condition changes (e.g., rain, flood, conflict or natural disaster)?

- What adjustments are needed when storage capacities change, either decreasing due to natural disaster or requirements of product (e.g. requiring ultra cold chain) or increasing with added cold chain when new refrigerators are added?

- How do I optimize distribution routes when a new vehicle is added or when a vehicle breaks down?

- How do I optimize distribution during an emergency or outbreak, or need for immediate distribution?

4. Demand: quantities of health products needed at each facility

5. Vehicle: vehicles available for use, including condition

6. Distance Data: matrix of distances between facilities

7. Road Condition: matrix of road conditions between facilities.

RoOT creates an output file in Microsoft Excel that details routes for each available vehicle, with departure times from each facility on its route, the complete list of health products to be delivered with quantities, and the estimated transport cost. There are two sheets in the Excel output file:

1. Routes: detailed description of each route and associated vehicle used to complete the distribution, including times leaving each health facility, utilization of vehicle capacity on each route, and fuel and per diem costs, and

2. Health products: detailed description of the quantity of health products transported by each vehicle on each route and delivered to each health facility.

A complete description of the inputs and outputs is available in the user's guide on GitHub ${ }^{25}$.

The optimization model in RoOT has two objectives and seven types of constraints, as summarized in Box 2. Our approach in 


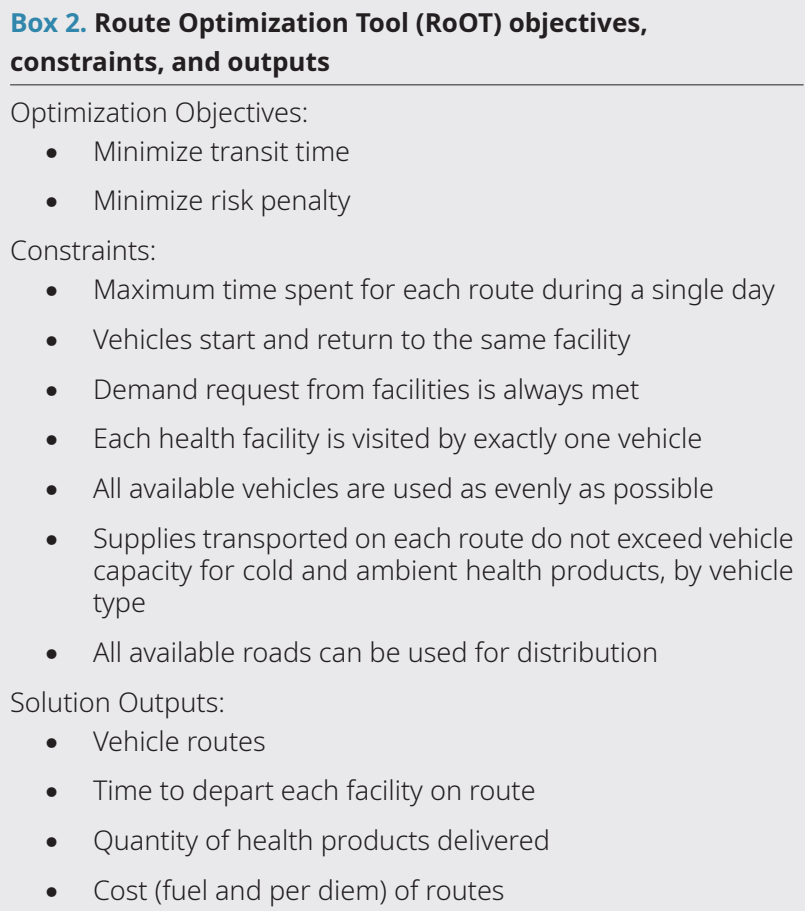

- Supplies transported on each route do not exceed vehicle capacity for cold and ambient health products, by vehicle type

- All available roads can be used for distribution

Solution Outputs:

- Vehicle routes

- Time to depart each facility on route

- Quantity of health products delivered

- Cost (fuel and per diem) of routes

RoOT is to allow the user to explore the trade-off between transit time and risk by providing two objective functions. The user can choose to minimize transit time or minimize risk by choosing penalties, and comparing the resulting routes. Alternately, users can also create an objective function by weighting transit time and risk to find a route that balances both objectives. The objective functions are described in more detail in the next section, Multiple objectives.

The constraints ensure that the routes can be practically implemented, such as only traveling on roads that are accessible, vehicles only carry supplies based on capacity, and supplies are provided based on demand at health facilities. A complete discussion is in the section Constraints and assumptions.

Based on user needs and the goal to have easy-to-use modeling tools, VillageReach and the University of Washington agreed on the requirements for the Route Optimization Tool (RoOT). The tool should:

- Be easy to use and easy to modify data by governments and technical partners and, hence, be based in Microsoft Excel.

- Be usable for routine operations, but also in emergency situations.

- Consider all health products, including those that need cold chain, such as vaccines that need to be kept at an ideal temperature range during transport.
- Consider the availability and reliability of vehicles.

- Consider the road conditions that may change seasonally (e.g. flooding) or in emergencies.

- Provide routes with departure times and quantities of health products for delivery.

- Minimize transit time and risk to vaccines.

- Calculate cost of routes.

- Execute quickly and provide results within minutes.

The steps we took to design an easy-to-use tool are described in the section Usability.

In addition to the tool being easy to use, it is also important that the tool provides a solution quickly, since most government users would not have the time to use a tool that would take hours to run. As described in more detail in the section Computational performance, we tested several available optimization algorithms and observed that it may take hours to produce a feasible solution, and even longer to determine an optimal solution. We decided to develop our own optimization algorithm that we could fine-tune to provide a solution to our optimization model quickly (see Computational performance).

\section{Multiple objectives}

Efficient distribution is critical in supply chains to ensure the supplies reach facilities in time and that there are no stockouts. Further, vehicles are often used for multiple purposes, such as supervision, training, outreach, asides from deliveries. Hence, minimize transit time was chosen as the first parameter or objective function available to the user. Most vaccines are also often at risk of spoilage during transit; this probability is also reduced by minimizing transit time.

It was also important to minimize the risk of temperature excursion by using the best available roads and vehicles during transport. Most vaccines need to be stored between $2-8^{\circ} \mathrm{C}$ and exposure to temperatures outside this range results in vaccines losing potency. Hence, even if vaccines or other temperaturesensitive commodities reach the service delivery point, but are not potent, they are not effective. Since vaccines are also at increased risk for losing potency if a vehicle breaks down en route, vehicle condition impacts risk. In addition, if a vehicle gets stuck on a road due to pot-holes or water on the road, road condition also impacts risk. Hence, road and vehicle condition are associated with penalties and defined in the second objective in the optimization model. This is a critical consideration for all vaccines, but more so for the COVID-19 vaccine given the specialized temperature requirements, high demand, limited supply, and associated costs related to vaccine procurement.

RoOT allows users to balance transit time with risk by entering a weight for transit time, denoted $W_{t}$, between 0 and 10 , and then the weight for risk, denoted $W_{p}$, which is calculated as $W_{p}=10-W_{t}$. The objective in RoOT is: 
minimize $W_{t}$ (transit time of all routes $)+W_{p}$ (risk for all routes $)$.

If the user enters $W_{t}=10$, then the model will only optimize transit time, and if $W_{t}=0$ then the model will only optimize the risk from unreliable roads and vehicles, whereas any value in between will balance minimizing transit time and risk.

\section{Constraints and assumptions}

The constraints of the optimization model in RoOT, as in Box 2, reflect the basic assumptions highlighted in Box 3.

RoOT only considers single-day routes used in distributions. The corresponding constraint is a maximum time limit for a route set by the user, must be less than 24 hours. The user can choose to set this for 24 hours, representing 3 days of 8 hours each. Figure 1 illustrates the "parameter" input sheet where the start time and return time is specified.

The second assumption is that vehicles start and return to the same distribution warehouse. Although vehicles for distribution may be available at different locations, they would need to pick up health products at a specified distribution warehouse. Hence, it is a reasonable constraint and assumption that each route starts from and returns to the distribution warehouse.

The model also assumes that there is sufficient supply of health products at the distribution warehouse to meet the demand requested by health facilities. If supply is limited, the user must adjust the requested demand in the input file. Therefore, a constraint in RoOT is that the total demand is met. An accompanying constraint in RoOT is that each health facility is visited exactly once by one vehicle.

RoOT will schedule as many routes as needed to fulfill the distribution. If only one vehicle is available, that vehicle may be assigned several routes, each route being completed within the limit set by the user. If more vehicles are available, RoOT assigns the number of routes to available vehicles as evenly as possible. For example, if two vehicles are available, a solution may assign two routes to one vehicle and one route to a second vehicle.

\section{Box 3. RoOT model assumptions}

The assumptions in the model are:

1. Distribution routes are completed within one day, a maximum 24-hour time period.

2. Vehicles start and return to the same distribution warehouse.

3. There is sufficient supply of health products at the distribution warehouse to meet the requested demand.

4. Health facilities can properly store the entire quantity of health products requested.

5. Distribution routes use roads which vehicles can access (transport over water or on foot is not considered).
RoOT assumes that the health facilities can properly store the quantity of health products requested. However, if the quantity requested by the facility exceeds its storage capacity, the model does not use this as a constraint. Instead, RoOT provides a warning to the user that the demand exceeds storage capacity, but it is still possible to execute the optimization model.

The constraints in the optimization model also include vehicle capacities for cold and ambient health products. Several types of vehicles are allowed, such as trucks, jeep, and motorcycles. For example, a motorcycle may be able to transport a small vaccine carrier with specific storage capacity for products requiring cold storage and have some space to carry other health products, like syringes or essential medicines. On the other hand, a refrigerated truck may be able to carry a larger quantity of products requiring cold storage and have capacity for other health products as well.

The last assumption is that the vehicles can travel on roads. To include distribution to an island that requires transport by boat, we selected a location that is accessible by land vehicles, and assumed that a boat would meet the vehicle at that location. A similar adjustment can be made to meet vehicles on roads if foot access is required. The constraints in the optimization model ensure that routes use roads that are accessible. A road that is in poor condition, but passable, is allowed and a penalty for the road condition is added into the risk objective function.

\section{Usability}

User centered design and ease-of-use was important in the tool from the very initial stages. There are several optimization and modeling supply chain tools available but, due to the design and complex interface, they are not easily used or adopted by government logisticians or technical partners that support governments. To focus on user centered design, we first mapped out the workflow for using the tool as shown in Figure 2, and analyzed the usability by using a modified version of Nielsen's Usability Heuristics ${ }^{26}$, which are an industry standard in usability studies.

Based on the workflow and principles of information architecture, three principles for improving the usability of the tool were identified: (1) reduce input data errors, (2) immediate feedback to users, and (3) reduce data input time.

To reduce user errors during data input, we used dropdown menus wherever possible for the user to select options from a list rather than typing them out or copying from another sheet, based on Nielsen's $1^{\text {st }}$ heuristic that users should get immediate feedback to make informed decisions, and $5^{\text {th }}$ heuristic that a system should be designed to prevent any errors. Hence, the RoOT Excel input file has dropdown menus for:

- selecting the start and return location for distribution,

- indicating whether a health product requires cold storage,

- vehicle availability and vehicle condition, and

- road condition 


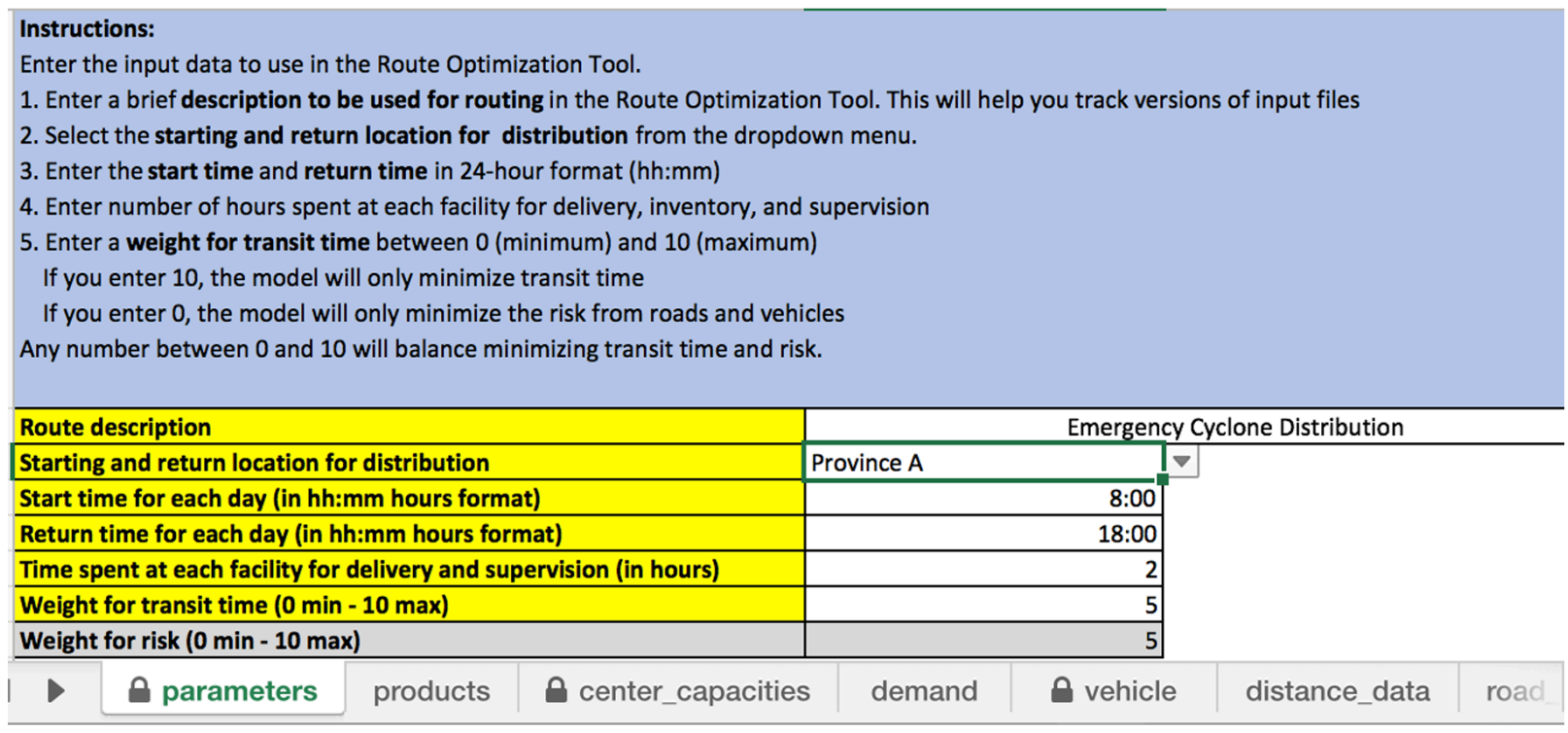

Figure 1. Spreadsheet for "parameters" input sheet, including the start and return location and times.

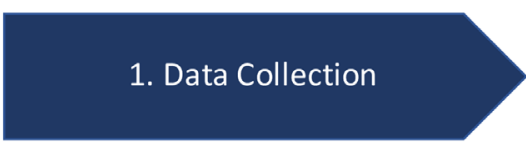

Excel Sheet

The overall Excel input file is specific to each location. There are seven sheets in each input file that capture attributes of each variable.

Users have to enter "accurate" data in each of the sheets.

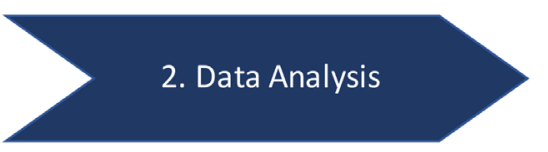

Program Input

The Excel input file is loaded as an input into a Python application (Windows based) for optimization.

Users have to start the application and select the input file to execute the optimization.

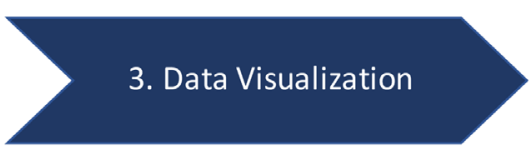

Program Output

An Excel output file is produced, with two output sheets.

Routes per day with selected attributes for the user are shown row-wise.

\section{Figure 2. Workflow for using RoOT.}

A common challenge with any tool using multiple databases is ensuring that facility names, products, and other input information are spelled consistently throughout so that the back-end algorithm can associate them. However, often facilities have multiple variations in spelling with slight changes across different databases. It is also tedious for the user to keep track of and correct spellings across multiple sheets or databases. To address this and make the data input process easier, the users enter the names of all facilities only once, in the "center_capacities" sheet, and the names are automatically replicated across all other sheets, reducing the chances of errors. Similarly, the names of health products are entered only once and automatically replicated across relevant sheets.
In addition to RoOT's user guide, we added brief instructions on every input sheet for easy reference by the user and to make data entry easier ${ }^{25}$. We also color-coded the cells to clearly indicate where the user needed to enter data, and where it was automatically calculated for pre-processing.

Further, to reduce the cognitive load on users when modifying the data, such as removing a vehicle from being considered for routing or dropping a specific health product, instead of relying on the user to manually copy or delete data, we included a yes/no dropdown for products and available/not available for vehicles to indicate whether the model should include them in the analysis based on Nielsen's $2^{\text {nd }}$ and $6^{\text {th }}$ heuristic ${ }^{26}$. This 
allows the user to enter data using words and phrases that they are familiar with, making data entry easy and reducing the chances of errors.

\section{Computational performance}

In operations research, it is well-established that the computation time to solve a vehicle routing problem, as in RoOT, increases significantly with the number of facilities to visit, as well as the number of available vehicles ${ }^{24}$. However, getting quick results within a few minutes was an essential requirement by users and, hence, we developed our own optimization algorithm for RoOT that is a variant of a Vehicle Routing and Scheduling Algorithm (VeRSA) ${ }^{27}$.

VeRSA embeds an indexing rule in a branch-and-bound framework to quickly construct a feasible solution in seconds, instead of hours. The routes that are determined in one or two minutes perform nearly as well as the optimal solutions that may take hours to determine. For RoOT, we adapted the indexing algorithm used in VeRSA for health product and vaccine distribution specifically. We also embedded specific constraints directly into the feasibility check in VeRSA to speed up computation. This version of VeRSA is coded in Python, and reads and writes Excel spreadsheets. Hence, the Python code is invisible to the user, making RoOT easy to use while providing timely results for logisticians.

In earlier versions of VeRSA, the number of products also increased computation time. However, in the final version of VeRSA used in RoOT, the computation was streamlined by aggregating the products into two categories: those requiring cold storage (such as vaccines) and those kept at ambient temperatures. The Python code disaggregates the two categories of products into specific names and quantities of products in the Excel output file. Thus, there is no limit to the number of products that can be input in RoOT as long as it fits in the two categories and it does not impact computation time in the optimization. Hence, RoOT can be used to plan routing for integrated health supply chains that deliver vaccines and other health products, such as family planning, malaria etc., together. RoOT can also be used in routing vaccines for campaign and routine immunization together, instead of distributing through parallel supply chains.

Computation time in modeling and routing software is an important factor for users. Commercial software can often take hours or days to obtain an optimal solution. However, government logisticians or technical partners supporting governments, often cannot run modeling problems for so long and often require quick solutions they can use. To understand the impact of number of health facilities on RoOT's computation time, we compared it with other commercially available software. The results showed that RoOT performed very well ${ }^{21}$. For 10-20 facilities, the performance of RoOT's indexing method was similar to the best of the commercial software packages and produced an optimal solution within 2 minutes. Hence, the default computation time in RoOT is set to 2 minutes. Additionally, we also tested RoOT for greater number of health facilities to reflect distributions in larger countries. For 50 health facilities, RoOT performed better than the commercial software, providing good results in 2 minutes while the commercial software took much longer ${ }^{21}$. For 100 facilities, RoOT determined a feasible solution within 2 minutes; however, this solution did not perform as well as a solution found after running a commercial software package for several hours. An advanced user can increase the default computation time of 2 minutes in the RoOT Excel input file, and in theory, RoOT will eventually obtain an optimal solution similar to commercial softwares. For practical purposes, we recommend using RoOT with 50 facilities or less to obtain optimal results in 2 minutes.

The number of vehicles used in the model also impacts computation time. To keep the computation time low keeping the user needs in mind, we recommend limiting the number of available vehicles to five or less. Based on our experience, we believe that five is a reasonable number as most provinces and districts in low- and middle-income countries often do not have more than five vehicles (with accompanying personnel) available to implement simultaneous routes. However, in a situation where more than five vehicles are available for distribution, it is possible to increase the number to more than five with the understanding that the computation time should be increased from the default of 2 minutes to provide a good solution.

The output generated by RoOT is similar to that of commercial solvers for relatively small datasets (10 or less health facilities), and RoOT provides a feasible solution faster than commercial solvers for large datasets (50 health facilities) based on a numerical comparison ${ }^{21}$. This confirms that RoOT gives good results in a timely manner that are correct and represents the information provided in the input files. It is also important to emphasize that unlike commercial solvers and most of the routing tools in the market, RoOT is open-source and freely available on GitHub (see Software availability section for details), in addition to being easy-to-use ${ }^{25}$.

\section{Operation}

RoOT is an open-source tool available online for free. The current tool runs on a Windows computer, 64-bit, with Microsoft Excel version 2007 or later. There are no specific RAM requirements, but the RoOT folder needs about $1.1 \mathrm{~GB}$ of memory. To check if your computer is 64-bit, go to "Display Settings" and scroll down to find "About" on the left menu. When you click on "About," you can see: "System type: 64-bit operating system."

\section{Challenges and limitations}

As with any modeling tool or software, the outputs are only as good as the input data. In many situations, accurate data may not be available and users have to fill data gaps using proxy data or by making assumptions. Some of the challenges and limitations of RoOT are outlined below.

Troubleshooting when RoOT does not run: RoOT is a light-touch Excel-based tool that is easy to run. However, if the data in the input file is incomplete, the model does not run or provide results. If this occurs, RoOT does not display any error message indicating to the user to check the input files for errors nor does it highlight what the error would be. We recommend that the user check each of the seven input sheets to make sure the data entered is correct and that no 
field is left blank. However, a challenge is that the burden of troubleshooting is put on the user.

Storage capacity of facilities: Currently RoOT does not limit distribution to facilities even if the demand exceeds the storage capacity available. This could be viewed as a challenge as the model is allowing distribution even when there are storage constraints. However, in practice, many facilities find ways to store health products beyond the officially designated space for storage, e.g. dry commodities are stored on top of cupboards or in corridors. To mitigate this challenge, we created a "warning" signal that provides users with real-time feedback on storage utilization based on the quantity of health products requested by a facility. This gives logisticians and supervisors insights about storage utilization, and if it exceeds capacity they could discuss with the facility, but the optimization can still be executed.

Using available vehicles: RoOT assigns routes to available vehicles, as evenly as possible, even though one vehicle may be more reliable than another one. For example, if two vehicles are available, and one is in good condition while the other is in poor condition, RoOT may assign two routes to the reliable vehicle and one route to the vehicle in poor condition, accomplishing the distribution in two days. If the user wants to explore the option of only using the vehicle in good condition, then the second vehicle should be selected as "unavailable" in the input sheet.

Multi-day routing: In practice, distributions of health products from provinces and districts to health facilities often take multiple days. However, the current model only allows for trips that can be completed within 24 hours. This limits the practical use of RoOT for distributions in areas which require multi-day routes, especially health facilities that are very far from the distribution warehouse and would take multiple days to reach. However, since the distribution can be done over 24 hours, the user can consider it as 3 days with 8 hours each. To expand RoOT capabilities further for multi-day routing, certain additional factors need to be considered such as overnight accommodation locations and maintaining cold chain overnight. These should be considered when expanding RoOT to allow multi-day trips.

Scalability to more health facilities: Currently RoOT is recommended for use for distributions to 50 facilities or less from a single distribution warehouse. This is a reasonable limitation, because distribution is often organized by administrative or distribution boundaries. If there are more than 50 facilities for distribution, the computation time can either be increased or facilities categorized by geographical proximity.

Matrix of distance between health facilities: One of the more challenging data to input for RoOT is completing a distance matrix as shown in Figure 3. The user needs to fill all the data, and cannot leave any cell empty in order to run the model.

This requires the user to look up and enter distances between each facility, and will be even more difficult as the number of health facilities increases. Mapping software, like Open Street Maps or Google maps, may be helpful in automatically creating a distance matrix as well in identifying shared roads, such as a highway or major arterial. However, health facilities in most LMICs are not easily located in mapping software, because either they are not marked or their names may be spelled differently making it challenging to use mapping software. This could be mitigated if geo-coordinates were available for health facilities making it easy to locate on mapping software; unfortunately, those are also not readily available. In system design studies using more sophisticated modeling software, we often have to search and lookup each health facility; and in circumstances when that is not available we often approximate to the district or province's location. While this continues to be a challenge, the user needs to only set up the distance matrix once and logisticians can also estimate the distance based on local knowledge.

\begin{tabular}{|c|c|c|c|c|c|c|c|c|c|c|}
\hline \multicolumn{3}{|c|}{$\begin{array}{l}\text { Instructions: } \\
\text { This sheet is set up as a matrix. Enter the distance between centers for } \\
\text { the model to calculate the optimal route. } \\
\text { 1. Enter the distance }(\mathrm{km}) \text { between each center. }\end{array}$} & 0 & \# & & & \multirow[b]{2}{*}{ Center E } & \multirow[b]{2}{*}{ Center $\mathbf{F}$} & \multirow[b]{2}{*}{ Center G } & \multirow[b]{2}{*}{$\mathrm{Ce}$} \\
\hline Centers & & & Province A & Center B & Center C & Center D & & & & \\
\hline Province A & & & & \begin{tabular}{|r|}
30 \\
\end{tabular} & \begin{tabular}{|r|}
36 \\
\end{tabular} & 12 & \begin{tabular}{|r|}
48 \\
\end{tabular} & 18 & 39 & \\
\hline Center B & & & 30 & & 54 & 42 & 33 & 39 & 18 & \\
\hline Center C & & & 36 & 54 & & 36 & 81 & 54 & 69 & \\
\hline Center D & & & 12 & 42 & 36 & & 57 & 21 & 54 & \\
\hline Center E & & & 48 & 33 & 81 & 57 & & 42 & 15 & \\
\hline Center F & & & 18 & 39 & 54 & 21 & 42 & & 39 & \\
\hline Center G & & & 39 & 18 & 69 & 54 & 15 & 39 & & \\
\hline Center H & & & 15 & 21 & 33 & 27 & 48 & 33 & 36 & \\
\hline Center I & & & 15 & 24 & 51 & 24 & 33 & 15 & 30 & \\
\hline Center J & & & 69 & 60 & 105 & 78 & 27 & 57 & 42 & \\
\hline Center K & & & 27 & 54 & 24 & 18 & 75 & 39 & 66 & \\
\hline parameters & products & center_capacitie & demar & and & vehicle & dista & ance_data & roa & + & \\
\hline
\end{tabular}

Figure 3. Distance matrix to fill in "distance_data" input sheet. 
Visualization of outputs: One of the requirements by users was the ability to visualize the outputs and see the routes on a map, but RoOT is currently limited to generating results in an Excel output file with no visualization. As mentioned above, it is challenging to integrate mapping software (e.g., Open Street Maps or Google maps) with RoOT, but is a possibility for future work.

\section{Use cases}

\section{Training logisticians in Mozambique}

RoOT is designed to meet the modeling needs of government stakeholders and users, including time available, resources, technology, ease of use and capabilities. To understand if our tool meets the requirements of the user, we trained eight logisticians in Mozambique representing provincial and district levels. We designed a four-step assessment to measure and understand how government users received the tool, based on the following questions:

1. Reaction: Do you like the tool and is it easy to use? This was measured through observation and survey.

2. Learning: Do trainees leave the training understanding how to use the tool? This was measured through a practical exercise and survey.

3. Behavior: Do logisticians actually use the tool to plan distributions?

4. Results: Does using the tool lead to better outcomes?

The participants of the training described that currently they follow pre-determined routes, starting either with the closest health facility or the largest one. Often, they find out which vehicle is available for distribution at the last minute when it arrives at the distribution facility, and they must quickly adjust the routes accordingly. The participants agreed that the tool was easy-to-use and would help them in distributions as illustrated from these quotes:

"We were creating the routes in an ad-hoc way. We didn't have a platform to guide us to calculate the routes and the quantities per route. This tool can help us by giving us different ways of arriving at the health facility."

"The truth is that we were working in the dark, we first tried something on the ground, then we would know the estimated cost and time, and whether that works or not; but with the tool, we're not in the dark. Calculating the time used in the distribution is one of the hardest things to do, as sometimes we don't know how to calculate whether we'll be able to return on the same day or the next; and this helps us calculate the time. But it should still consider the fact that you sometimes have to come back the next day, not always on the same day."

“... the tool tells us what is the capacity at each health facility also helps us to visualize. We used to load vaccines according to needs only and not take into account what is the actual capacity at the health facility."

Over $60 \%$ of the logisticians in the training rated their confidence to use the tool as skillful, i.e., they could use the tool independently with occasional help from a specialist. Out of the eight participants, seven were confident in being able to use the tool to determine routes and to decide which vehicles to use. The logisticians confirmed that they would be able to use the Portuguese version of the tool for routine and emergency distribution. Unfortunately, due to the COVID-19 pandemic in 2020, the full deployment of RoOT has been delayed.

\section{Using RoOT for distributions during an emergency}

RoOT is designed to meet the needs of government stakeholders for routine as well as emergency distributions. For routine distribution, we anticipate that logisticians would use the tool to determine a number of consistently-used routes, updated with current road and vehicle conditions.

RoOT can also be used for emergency situations, like outbreaks or campaigns when a new health product needs to reach health facilities quickly. As supplies and treatments for COVID-19 become available or a new vaccine is introduced, governments will need to mobilize quickly to make sure the vaccine and health products are getting to the most vulnerable people as soon as possible. Even though manufacturers are trying to build capacity for a new vaccine, there will be supply shortages as all countries strive to procure it. Hence, countries will need to prioritize how many vaccines to deliver and to which health facilities in the fastest way possible, while reducing the risk to potency. RoOT can be used to quickly determine and plan routes based on minimizing transit time and risk, to align with government priorities.

To illustrate the use of RoOT in an emergency situation, we consider a natural disaster, such as a cyclone. In an emergency situation, there are several parameters that a logistician may need to assess and modify. In this cyclone scenario, distributions need to take place from a different warehouse than what is typically used. In addition, several health facilities cannot accept supplies because their storage capability has been destroyed, and several roads are not accessible anymore.

Step 1: Changing distribution warehouse location. The user would change the start and return location for distribution in the "parameters" input sheet by selecting another facility from the dropdown menu. As shown in Figure 4, the distribution location has changed from Province A to Center B.

Step 2: Updating demand for health facilities. Given the emergency situation, not all health facilities are intact or have storage for supplies. Hence, health products need to be distributed to a smaller number of health facilities that may see an upsurge in demand as people from nearby areas are also traveling there to seek care. The logistician does this in RoOT by changing the demand to zero for health facilities that are not able to store supplies at this time, and accordingly increases demand for other facilities. As shown in Figure 5, Province A, Center $\mathrm{C}$ and Center D have zero demand, and demand has increased for Center B and Center F.

Step 3: Updating road conditions. In case of a natural disaster, like a cyclone, many of the road conditions may change or 


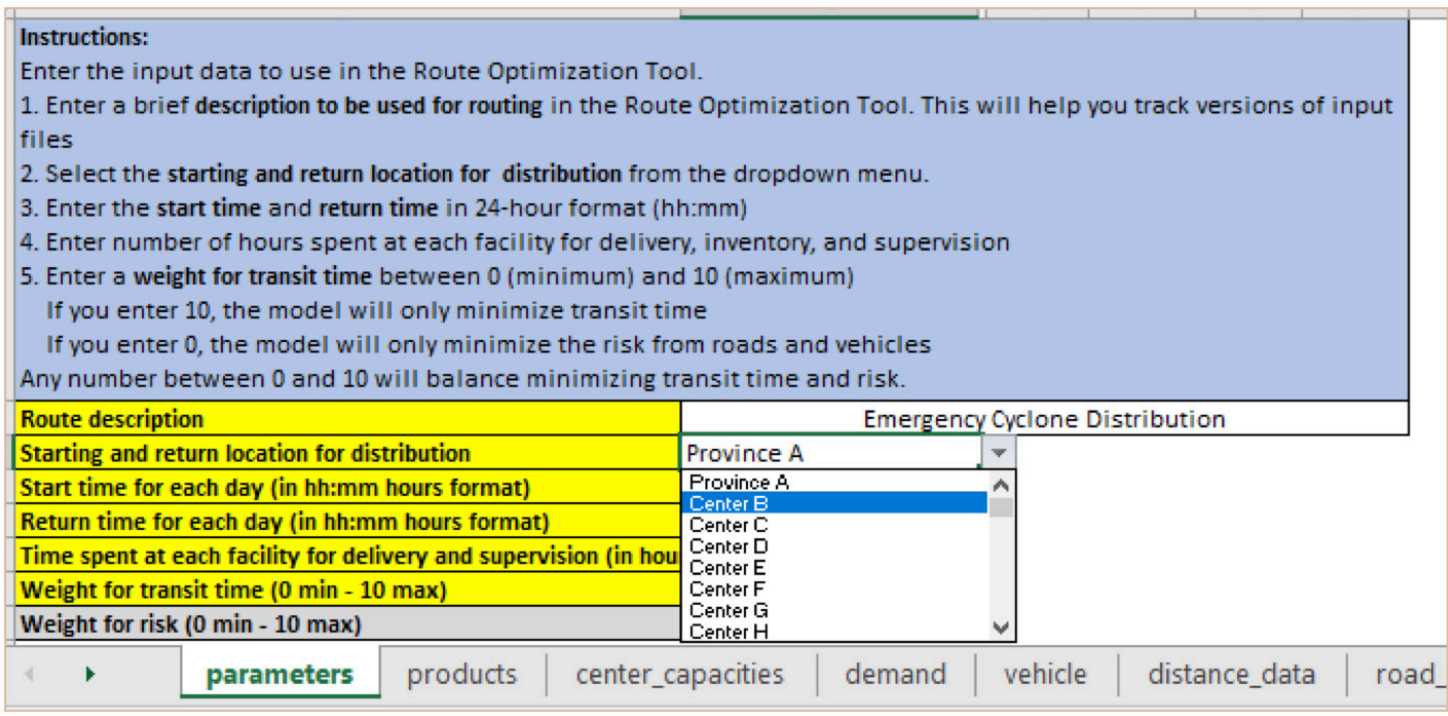

Figure 4. Change the distribution warehouse location from Province A to Center B in the "parameters" input sheet.

\begin{tabular}{|c|c|c|c|c|c|c|c|c|c|c|}
\hline \multicolumn{11}{|c|}{$\begin{array}{l}\text { Instructions: } \\
\text { Use this shee }\end{array}$} \\
\hline \multicolumn{11}{|c|}{$\begin{array}{l}\text { There are two warning columns that indicate if the requested demand for refrigerated and non-refrigerated products exceeds } \\
\text { center capacity. The utilization of capacity (in percentage) is calculated. } \\
\text { If the demand exceeds the center capacity, the warning column will turn from green to red. If you see the warning, adjust the } \\
\text { demand to make sure the center has capacity to store it. The Route Optimization Tool can still be run even with the warning. }\end{array}$} \\
\hline & & \multicolumn{2}{|c|}{\begin{tabular}{|l|}
$\begin{array}{l}\text { Warning for } \\
\text { refrigerated capacity }\end{array}$ \\
\end{tabular}} & \multicolumn{2}{|c|}{\begin{tabular}{|l|} 
Warning for \\
non-refrigerated
\end{tabular}} & PR1 & $\mathrm{PR} 2$ & PR3 & PRi4 & PR5 \\
\hline Centers & & \multicolumn{2}{|c|}{$\begin{array}{l}\text { Utilized refrigerated } \\
\text { capacity }\end{array}$} & \multicolumn{2}{|c|}{$\begin{array}{l}\text { Utilized non-refrigerated } \\
\text { capacity }\end{array}$} & Measles & BCG & Penta-1 & Penta-10 & PCV10 \\
\hline Province A & & \multicolumn{3}{|c|}{$2.1 \%$} & $7.6 \%$ & 0 & 0 & 0 & 0 & 0 \\
\hline Center B & & \multicolumn{3}{|c|}{$20.4 \%$} & $3.3 \%$ & 71 & 14 & 38 & 19 & 273 \\
\hline Center C & & \multicolumn{3}{|c|}{$0.9 \%$} & $3.0 \%$ & 0 & 0 & 0 & 0 & 0 \\
\hline Center D & & \multicolumn{3}{|c|}{$0.4 \%$} & $0.8 \%$ & 0 & 0 & 0 & 0 & 0 \\
\hline Center $\mathrm{E}$ & & \multicolumn{3}{|c|}{$2.6 \%$} & $0.3 \%$ & 3 & 1 & 2 & 1 & 13 \\
\hline Center $\mathrm{F}$ & & \multicolumn{3}{|c|}{$4.9 \%$} & $0.8 \%$ & 14 & 3 & 8 & 4 & 55 \\
\hline Center G & & \multicolumn{3}{|c|}{$3.1 \%$} & $0.7 \%$ & 7 & 1 & 4 & 2 & 28 \\
\hline • & parameters & products & center_cap & pacities & demand & vehicle & & tance_dat & & ad_condi \\
\hline
\end{tabular}

Figure 5. Change the demand for health facilities; set demand to zero for facilities that are not able to store health products at this time and adjust demand for other facilities.

become completely inaccessible due to flooding or destruction, making them unavailable for use. The logistician planning the routes can select the updated road conditions from a list of options in a dropdown menu, as seen in Figure 6, where the road from Center B to Center E is not accessible. The dropdown menu allows the selection from the following options: Fully paved, Partially paved, Dirt road (Good Quality), Dirt road (Rough), and Not accessible.
Step 4: Run RoOT for updated results. After making all the changes to the inputs, the user should save the input file and re-run RoOT. The tool will provide results within 2 minutes, and generate an Excel output file displaying the routes, departure times, and health products that need to be delivered for the emergency situation. Figure 7 illustrates the new routes for the cyclone scenario. There are three routes that start and end at Center B. There are two vehicles available for distribution, the 


\begin{tabular}{|c|c|c|c|c|c|c|c|}
\hline \multicolumn{8}{|c|}{$\begin{array}{l}\text { Instructions: } \\
\text { This sheet is set up as a matrix. Use the dropdown to select the condition of the road between centers for the model to assess the risk } \\
\text { of using that road. } \\
\text { 1. Enter condition of the road between centers using dropdown menu. }\end{array}$} \\
\hline Centers & Province A & Center B & Center C & Center D & Center E & Center $\mathrm{F}$ & Center G \\
\hline \multirow{2}{*}{$\begin{array}{l}\text { Province A } \\
\text { Center B }\end{array}$} & & Fully paved & Partially paved & Not accessible & Not accessible & Fully paved & Fully paved \\
\hline & \begin{tabular}{|l|} 
Fully paved \\
\end{tabular} & & Fully paved & Fully paved & Fully paved & - t road (Rough) & Not accessible \\
\hline Center C & \begin{tabular}{|l} 
Dirt road (Rough) \\
\end{tabular} & Fully paved & & Not accessible & \multirow{3}{*}{$\begin{array}{l}\text { Fully paved } \\
\text { Partially paved } \\
\text { Dirt road (Good Quality) } \\
\text { Dirt road (Rough) }\end{array}$} & lly paved & Not accessible \\
\hline Center D & Fully paved & Not accessible & Fully paved & & & ity) tt accessible & Fully paved \\
\hline Center E & Dirt road (Rough) & Partially paved & Dirt road (Rough) & Fully paved & & lly paved & Partially paved \\
\hline Center $\mathrm{F}$ & Fully paved & Dirt road (Rough) & Partially paved & Partially paved & \multicolumn{2}{|l|}{\begin{tabular}{|l|} 
Not accessible \\
Dirt road (Rough)
\end{tabular}} & Fully paved \\
\hline Center $\mathrm{G}$ & \begin{tabular}{|l|} 
Not accessible \\
\end{tabular} & Not accessible & Fully paved & Fully paved & \begin{tabular}{|l|l|l|} 
Fully paved & $\mathrm{N}$ \\
\end{tabular} & Not accessible & \\
\hline$\ldots$ & products & ter_capacities & vehicle & distance_data & road_condition & $\uplus$ & \\
\hline
\end{tabular}

Figure 6. Update the "road_condition" input sheet to reflect current road conditions and accessibility between Centers.

\begin{tabular}{|l|l|l|}
\hline $\begin{array}{l}\text { ROUTE } \\
\text { DESCRIPTION: }\end{array}$ & Emergency Cyclone Distribution & OUTPUT SHEET 1 OF 2 \\
\hline
\end{tabular}

\section{SUMMARY ROUTE AND PRODUCT DISTRIBUTION}

\begin{tabular}{|r|l|r|l|l|l|}
\hline $\begin{array}{l}\text { TOTAL } \\
\text { DISTANCE }(\mathrm{Km}):\end{array}$ & $\begin{array}{l}\text { TOTAL FUEL } \\
\text { COST: }\end{array}$ & $\begin{array}{l}\text { TOTAL PER } \\
\text { DIEM COST: }\end{array}$ & $\begin{array}{l}\text { TOTAL COST } \\
\text { (FUEL + PER } \\
\text { DIEM): }\end{array}$ & $\begin{array}{l}\text { TOTAL } \\
\text { DOSES } \\
\text { DELLIVERED: }\end{array}$ & $\begin{array}{l}\text { COST PER } \\
\text { DOSE: }\end{array}$ \\
\hline $\mathbf{5 7 6}$ & $\mathbf{4 5 9 7 . 6 3}$ & $\mathbf{6 0 0}$ & $\mathbf{5 1 9 7 . 6 3}$ & $\mathbf{1 4 7 0}$ & $\mathbf{3 . 5 4}$ \\
\hline
\end{tabular}

DETAILED ROUTE INFORMATION FOR 3 ROUTES

\begin{tabular}{|l|l|l|r|r|l|l|l|l|l|}
\hline ROUTE: & VEHICLE: & $\begin{array}{l}\text { VEHICLE } \\
\text { CONDITION: }\end{array}$ & $\begin{array}{l}\text { DISTANCE FOR } \\
\text { ROUTE }(\text { Km): }\end{array}$ & \begin{tabular}{ll|l} 
FUEL COST \\
FOR ROUTE:
\end{tabular} & $\begin{array}{l}\text { PER DIEM } \\
\text { COST FOR } \\
\text { ROUTE: }\end{array}$ & $\begin{array}{l}\text { TOTAL } \\
\text { DOSES } \\
\text { DELIVERED: }\end{array}$ & $\begin{array}{l}\text { TOTAL COST } \\
\text { PER DOSE: }\end{array}$ & $\begin{array}{l}\text { REFRIGERATED } \\
\text { UTILIZATION } \\
\text { OF VEHICLE } \\
\text { (\%): }\end{array}$ & $\begin{array}{l}\text { NON- } \\
\text { REFRIGERATED } \\
\text { UTILIZATION OF } \\
\text { VEHICLE (\%): }\end{array}$ \\
\hline Route 1 & Landcruiser_3PL & $\begin{array}{l}\text { Always } \\
\text { Reliable }\end{array}$ & 234 & 1867.79 & 200 & 200 & 10.34 & 1.8 & 360 \\
\hline
\end{tabular}

\begin{tabular}{|l|l|l|}
\hline CENTERS: & $\begin{array}{l}\text { TIME TO } \\
\text { LEAVE THE } \\
\text { CENTER: }\end{array}$ & ROAD CONDITION: \\
\hline Center B & $8 \mathrm{~h} 0 \mathrm{~min}$ & Fully paved \\
\hline Center D & $10 \mathrm{~h} 42 \mathrm{~min}$ & Fully paved \\
\hline Center E & $13 \mathrm{~h} 39 \mathrm{~min}$ & Dirt road (Rough) \\
\hline Center C & $17 \mathrm{~h} 0 \mathrm{~min}$ & Fully paved \\
\hline Center B & \multicolumn{3}{|l}{} \\
& &
\end{tabular}

\begin{tabular}{|l|l|l|r|r|l|l|l|l|l|}
\hline ROUTE: & VEHICLE: & $\begin{array}{l}\text { VEHICLE } \\
\text { CONDITION: }\end{array}$ & $\begin{array}{l}\text { DISTANCE FOR } \\
\text { ROUTE }(\text { FUm): }\end{array}$ & $\begin{array}{l}\text { FUEL COST ROUTE: } \\
\text { FOR ROAT }\end{array}$ & $\begin{array}{l}\text { PER DIEM } \\
\text { COST FOR } \\
\text { ROUTE: }\end{array}$ & $\begin{array}{l}\text { TOTAL } \\
\text { DOSES } \\
\text { DELIVERED: }\end{array}$ & $\begin{array}{l}\text { TOTAL COST } \\
\text { PER DOSE: }\end{array}$ & $\begin{array}{l}\text { REFRIGERATED } \\
\text { UTILIZATION } \\
\text { OF VEHICLE } \\
\text { (\%): }\end{array}$ & $\begin{array}{l}\text { NON- } \\
\text { REFRIGERATED } \\
\text { UTILIZATION OF } \\
\text { VEHICLE (\%): }\end{array}$ \\
\hline Route 2 & NEW VEHICLE & $\begin{array}{l}\text { Sometimes } \\
\text { Reliable }\end{array}$ & 222 & 1772 & 200 & 700 & 2.82 & 1.8 & 360 \\
\hline
\end{tabular}

\begin{tabular}{|l|l|l|}
\hline CENTERS: & $\begin{array}{l}\text { TIME TO } \\
\text { LEAVE THE } \\
\text { CENTER: }\end{array}$ & ROAD CONDITION: \\
\hline Center B & $8 \mathrm{~h} \mathrm{0} \mathrm{min}$ & Fully paved \\
\hline Center J & $11 \mathrm{~h} \mathrm{0} \mathrm{min}$ & Fully paved \\
\hline Center G & $13 \mathrm{~h} 42 \mathrm{~min}$ & Fully paved \\
\hline Center $\mathrm{K}$ & $16 \mathrm{~h} 48 \mathrm{~min}$ & Fully paved \\
\hline \multicolumn{2}{|l}{ Center B } & \multicolumn{2}{|l}{} \\
\cline { 2 - 2 }
\end{tabular}

\begin{tabular}{|l|l|l|r|r|l|l|l|l|l|}
\hline ROUTE: & VEHICLE: & $\begin{array}{l}\text { VEHICLE } \\
\text { CONDITION: }\end{array}$ & $\begin{array}{l}\text { DISTANCE FOR } \\
\text { ROUTE }(\mathrm{Km}):\end{array}$ & FUEL COST \\
FOR ROUTE: & $\begin{array}{l}\text { PER DIEM } \\
\text { COST FOR } \\
\text { ROUTE: }\end{array}$ & $\begin{array}{l}\text { TOTAL } \\
\text { DOSES } \\
\text { DELIVERED: }\end{array}$ & $\begin{array}{l}\text { TOTAL COST } \\
\text { PER DOSE: }\end{array}$ & $\begin{array}{l}\text { REFRIGERATED } \\
\text { UTILIZATION } \\
\text { OF VEHICLE } \\
\text { (\%): }\end{array}$ & $\begin{array}{l}\text { NON- } \\
\text { REFRIGERATED } \\
\text { UTILIZATION OF } \\
\text { VEHICLE (\%): }\end{array}$ \\
\hline Route 3 & NEW VEHICLE & $\begin{array}{l}\text { Sometimes } \\
\text { Reliable }\end{array}$ & 120 & 957.84 & 200 & 570 & 2.03 & 2.4 & 480 \\
\hline
\end{tabular}

\begin{tabular}{|l|l|l|}
\hline CENTERS: & $\begin{array}{l}\text { TIME TO } \\
\text { LEAVE THE } \\
\text { CENTER: }\end{array}$ & ROAD CONDITION: \\
\hline Center B & $8 \mathrm{~h} 0 \mathrm{~min}$ & Fully paved \\
\hline Province $\mathrm{A}$ & $10 \mathrm{~h} 30 \mathrm{~min}$ & Fully paved \\
\hline Center $\mathrm{H}$ & $12 \mathrm{~h} 45 \mathrm{~min}$ & Fully paved \\
\hline Center $\mathrm{I}$ & $15 \mathrm{~h} 6 \mathrm{~min}$ & Fully paved \\
\hline Center $\mathrm{F}$ & $17 \mathrm{~h} 21 \mathrm{~min}$ & Dirt road (Rough) \\
\hline Center B & \multicolumn{2}{|l}{} \\
\end{tabular}

Figure 7. New routes for emergency cyclone distribution with two available vehicles. 
Landcruiser_3PL, and a New Vehicle. As shown in Figure 7, the Landcruiser_3PL leaves Center B at 8am, and visits Centers D, $\mathrm{E}$, and $\mathrm{C}$ before returning to Center B. The New Vehicle has two routes, as illustrated in Figure 7. Notice that these three routes never use any roads that are marked "Not Accessible" using the dropdown menu in the input sheet in Figure 6.

\section{Conclusions}

In conclusion, RoOT is an easy-to-use optimization tool that enables logisticians to quickly plan and adjust routes for health product distribution accounting for transit time and risk of temperature excursion of sensitive products, such as vaccines. RoOT is designed to

- meet the requirements of government stakeholders, and

- provide faster results than commercial software

As users gain experience with RoOT, they will identify several areas for future improvements. One possibility is to integrate RoOT with existing software tools (such as demand projections and cost analyses) to increase consistency of data inputs. At the same time, it is desirable to maintain independent use of RoOT so it is easily transferable to many countries and many types of health products. Another future extension is to consider multi-day routes, where many considerations must be discussed and appropriate assumptions and constraints developed. Lastly, inclusion of visualization with mapping software will greatly improve the usability of RoOT.

\section{Software availability}

Route Optimization Tool (RoOT), with user guide and underlying data is available from: https://github.com/villagereach/RoOT (in English) and https://github.com/villagereach/RoOT-portugues (in Portuguese).

Archived source code available from: http://doi.org/10.5281/ zenodo. $4477538^{28}$

\section{License: GNU General Public License}

\section{Acknowledgements}

The authors thank the Government of Mozambique for providing input in the development and use of this tool, specifically Delísio Acácio Machava (Provincial EPI Manager, Provincial Health Directorate) and his team, who were engaged during the whole process. We especially acknowledge the feedback from the logisticians from Maputo City and Maputo Province. In addition, this tool benefited from practical experience and inputs on supply chain distribution and testing from Abel Draiva and Alvaro S. Lopes from VillageReach Mozambique. We thank Turam Purty, student at the Information School of University of Washington, for his inputs on improving the usability of the tool. We also thank Yi Chu, student at the University of Washington, for his assistance in collaboratively developing and coding the algorithm in the tool.
1. Value of vaccination: Gavi, the Vaccine Alliance. 2019. Reference Source

2. Ozawa S, Clark S, Portnoy A, et al.: Return on investment from childhood immunization in low- and middle-income countries, 2011-20. Health Aff (Millwood). 2016; 35(2): 199-207. PubMed Abstract | Publisher Full Text

3. World Health Organization: 2018 Assessment report of the Global Vaccine Action Plan. Strategic Advisory Group of Experts on Immunization. Geneva: World Health Organization; (WHO/IVB/18.11). Licence: CC BY-NC-SA 3.0 IGO. 2018:(WHO/IVB/18.11). 2018. Reference Source

4. Prosser W, Phillips N, McWhorter R, et al:: A System Design Approach for Comprehensive Immunization Supply Chain Strengthening A Case Study from Mozambique. Seattle and Copenhagen: VillageReach and UNICEF. 2016. Reference Source

5. Lee BY, Haidari LA, Prosser W, et al.: Re-designing the Mozambique vaccine supply chain to improve access to vaccines. Vaccine. 2016; 34(41): 4998-5004. PubMed Abstract | Publisher Full Text | Free Full Text

6. Prosser W, Jaillard P, Assy E, et al:: System redesign of the immunization supply chain: Experiences from Benin and Mozambique. Vaccine. 2017 35(17): 2162-2166. PubMed Abstract | Publisher Full Text

7. Zameer M, Phillips-White N, Folorunso O, et al:: Promoting equity in immunization coverage through supply chain design in Pakistan. [version 1; peer review: 1 approved, 1 approved with reservations]. Gates Open Res. 2020; 4: 31. Publisher Full Text

8. Wirkas T, Toikilik S, Miller N, et al:: A vaccine cold chain freezing study in PNG highlights technology needs for hot climate countries. Vaccine. 2007; 25(4): 691-697.

PubMed Abstract | Publisher Full Text

9. Yauba $\mathrm{S}$, Joelle $\mathrm{S}$, Jude $\mathrm{N}$, et al.: Temperature Monitoring in the Vaccine Cold Chain in Cameroon. J Vaccines Vaccin. 2018; 09(01): 384. Publisher Full Text
10. Nelson $\mathrm{CM}$, Wibisono $\mathrm{H}$, Purwanto $\mathrm{H}$, et al: : Hepatitis $\mathbf{B}$ vaccine freezing in the Indonesian cold chain: Evidence and solutions. Bull World Health Organ. 2004; 82(2): 99-105.

PubMed Abstract | Free Full Text

11. Baharmand $\mathrm{H}$, Comes $\mathrm{T}$, Lauras $\mathrm{M}$ : Managing in-country transportation risks in humanitarian supply chains by logistics service providers: Insights from the 2015 Nepal earthquake. Int J Disaster Risk Reduct. 2017; 24: 549-559. Publisher Full Text

12. Özdamar L, Ertem MA: Models, solutions and enabling technologies in humanitarian logistics. Eur J Oper Res. 2015; 244(1): 55-65. Publisher Full Text

13. Hamedi M, Haghani A, Yang S: Reliable Transportation of Humanitarian Supplies in Disaster Response: Model and Heuristic. Procedia-Soc Behav Sci. 2012; 54: 1205-1219. Publisher Full Text

14. Nolz PC, Semet F, Doerner KF: Risk approaches for delivering disaster relief supplies. OR Spectr. 2011; 33(3): 543-569. Publisher Full Text

15. Akgün $\mathrm{V}$, Parekh $\mathrm{A}$, Batta $\mathrm{R}$, et al.: Routing of a hazmat truck in the presence of weather systems. Comput Oper Res. 2007; 34(5): 1351-1373. Publisher Full Text

16. List GF, Mirchandani PB, Turnquist MA, et al: Modeling and Analysis for Hazardous Materials Transportation: Risk Analysis, Routing/Scheduling and Facility Location. Transp Sci. 1991; 25(2): 99-174. Publisher Full Text

17. Batta R, Chiu SS: Optimal Obnoxious Paths on a Network: Transportation of Hazardous Materials. Oper Res. 1988; 36(1): 84-92. Reference Source

18. Saccomanno FF, Chan AYW: Economic Evaluation of Routing Strategies for Hazardous Road Shipment. Transp Res Rec. 1985; 1020: 12-18. Reference Source

19. Hanson CM, George AM, Sawadogo A, et al.: Is freezing in the vaccine cold 
chain an ongoing issue? A literature review. Vaccine. 2017; 35(17): 2127-2133.

PubMed Abstract | Publisher Full Text

20. Vitoriano B, Montero J, Ruan D: Decision Aid Models for Disaster Management and Emergencies. 2013.

Reference Source

21. Petroianu LPG, Zabinsky ZB, Zameer $M$, et al.: A light-touch routing optimization tool (RoOT) for vaccine and medical supply distribution in Mozambique. Intl Trans in Op Res. 2020. Publisher Full Text

22. LLamasoft - Supply Chain Guru® Cloud-Based Supply Chain Design Software. 2020 Reference Source

23. Global Logistic Competence (GLC) Reference Source
24. Laporte G: The Vehicle Routing Problem: An overview of exact and approximate algorithms. Eur J Oper Res. 1992; 59(3): 345-358. Publisher Full Text

25. User Guide: Route Optimization Tool (RoOT) Reference Source

26. Nielsen J, Mack RL: Usability Inspection Methods. (Nielsen, Jakob and Mack RL ed.). New York, USA: John Wiley \& Sons, Inc. 1994 Reference Source

27. Zabinsky ZB, Dulyakupt $\mathrm{P}$, Zangeneh-Khamooshi S, et al: Optimal collection of medical specimens and delivery to central laboratory. Ann Oper Res. 2020; 287: 537-564.

Publisher Full Text

28. Ipetroia: villagereach/RoOT: Release 2020-01-28 (Version rel-2020-01-28). Zenodo. 2021.

http://www.doi.org/10.5281/zenodo.4477538 


\section{Open Peer Review}

\section{Current Peer Review Status: ? ? ?}

Version 1

Reviewer Report 06 April 2021

https://doi.org/10.21956/gatesopenres.14437.r30466

(C) 2021 Inglis A. This is an open access peer review report distributed under the terms of the Creative Commons Attribution License, which permits unrestricted use, distribution, and reproduction in any medium, provided the original work is properly cited.

\section{Andrew Inglis}

USAID Global Health Supply Chain Programme, Procurement and Supply Management, International Business Machines, Arlington, VA, USA

Firstly, I believe the authors have developed and demonstrated an innovative approach to solving a routing problem for distribution in a development context.

My main reservations relate to questions 4 and 5:

Is sufficient information provided to allow interpretation of the expected output datasets and any results generated using the tool?

Are the conclusions about the tool and its performance adequately supported by the findings presented in the article?

The comparison against other routing options seams to be focused on other commercial options saying "Most of the routing software used in commercial logistics focuses on distribution efficiency to minimize cost and time" - no mention or consideration for other low cost / open source options that are currently available, e.g. https://www.graphhopper.com/ or https://openrouteservice.org/. It would be better for the reader to know that there are other options.

I reviewed the reference (21 - Petroianu LPG, Zabinsky ZB, Zameer M, et al.: A light-touch routing optimization tool (RoOT) for vaccine and medical supply distribution in Mozambique. Intl Trans in Op Res. 2020) - provided to support the following statement "To understand the impact of number of health facilities on RoOT's computation time, we compared it with other commercially available software. The results showed that RoOT performed very well21".

I did not find a table or data that showed computational time between Commercial software and RoOT. I did find against different solvers - Gurobi, CBC and GLPK - how that is not the same as comparison to commercial software. The paper then indicates it did analysis against commercial software: "For 10-20 facilities, the performance of RoOT's indexing method was similar to the best of the commercial software packages and produced an optimal solution within 2 minutes. Hence, the default computation time in RoOT is set to 2 minutes. Additionally, we also tested RoOT for greater number of health facilities to reflect distributions in larger countries. For 50 health 
facilities, RoOT performed better than the commercial software, providing good results in 2 minutes while the commercial software took much longer ${ }^{21}$. For 100 facilities, RoOT determined a feasible solution within 2 minutes; however, this solution did not perform as well as a solution found after running a commercial software package for several hours."

Therefore, since they did this analysis it would be good to include this data within the paper for the reader to see and understand the differences. Additionally, when the default computation time in RoOT is set to 2 minutes, the same setting for computation time could be set for commercial software and then comparison would be on how well the solutions were after 2 mins determined between RoOT and the commercial software. Thus, we don't know if the solution calculated after 2 mins was similar or not between RoOT or the Commercial Software; having this information this would strengthen the evidence.

"Computation time in modeling and routing software is an important factor for users. Commercial software can often take hours or days to obtain an optimal solution." Further context to this statement would be useful to the reader, if you are looking to solve a large routing problem to fully optimal solution then it will take time if using the RoOT or Commerical Software or other open source routing software. Just saying "Commercial software can often take hours or days" without context is misleading. This is then shown when context is then provided in the paper. The paper states for a small problem "For 10-20 facilities, the performance of RoOT's indexing method was similar to the best of the commercial software packages and produced an optimal solution within 2 minutes" thus they take the same time. Then for a slightly larger problem "For 50 health facilities, RoOT performed better than the commercial software, providing good results in 2 minutes while the commercial software took much longer ${ }^{21}$." This is the "sweet spot" for this tool and thus should emphasized as in the environment this tool is to be deployed in there are a number of distribution points that could meet this criterion. Then for a larger problem "For 100 facilities, RoOT determined a feasible solution within 2 minutes; however, this solution did not perform as well as a solution found after running a commercial software package for several hours", this where you are starting to step out of the "sweet spot", however as described in the paper for practical purposes it is good enough. Thus, the importance for having that table to demonstrate the difference in computation time.

On the Distance Matrix the paper does recognize the challenge in filling this out. Suggestion is to mention such resources to support the distance matrix https://openrouteservice.org/ that provides distance matrix, this could be useful as it is designed to work in this context.

Additionally, "Updating road conditions" is a simplification of the impact and ease of determining which paths between different sites have been affected by a disaster or change in the road conditions. A change in road condition is unlikely to just affect one pair of sites as described in the paper, it would need to be determined if and how affect all paths to a site across matrix. For example if a road is inaccessible "from Center B to Center E is not accessible" it could affect the paths between all sites to $B$ and/or all sites to $E$. As it is unlikely to have a single path that is only between sites $B$ and $E$, it is more common that sites will share a road with other paths to sites, thus when a road is affected then it will be across multiple sites. Thus, it would be good to clarify and expand the current clarification on how to update the road conditions and ensure that readers understand what needs to be done when inputting updates to road conditions.

\section{Is the rationale for developing the new software tool clearly explained?}


Yes

Is the description of the software tool technically sound?

Yes

Are sufficient details of the code, methods and analysis (if applicable) provided to allow replication of the software development and its use by others?

Yes

Is sufficient information provided to allow interpretation of the expected output datasets and any results generated using the tool?

Partly

Are the conclusions about the tool and its performance adequately supported by the findings presented in the article?

Partly

Competing Interests: No competing interests were disclosed.

I confirm that I have read this submission and believe that I have an appropriate level of expertise to confirm that it is of an acceptable scientific standard, however I have significant reservations, as outlined above.

Author Response 26 Oct 2021

Mariam Zameer, VillageReach, Seattle, USA

1. We have added Graphhopper and Openrouteservice to the paper. Thank you for highlighting this.

2. The reviewer makes a good point to distinguish "commercial software" with "solvers". We have clarified this in the text.

3. Thank you for this suggestion to fill out the Distance Matrix. We added, "Mapping software, like Open Street Maps, Google maps, or https://openrouteservice.org/ ..."

4. We added on updating road conditions, "If a road is blocked due an emergency or some other reason, the user updated it on the "road_condition" input sheet (Figure 6) to 'Not accessible'. RoOT will not use this road while creating a route, and determine alternative routes. If the blocked road is used by several facilities, it must also be changed to 'Not accessible' in the distance matrix. If a facility is completely inaccessible by existing roads, a make-shift facility can be created to the point which is accessible by road."

We would be glad and eager to work with openrouteservice in the future, to improve this.

Competing Interests: No competing interests were disclosed. 
Reviewer Report 24 March 2021

https://doi.org/10.21956/gatesopenres.14437.r30465

(C) 2021 McWhorter R. This is an open access peer review report distributed under the terms of the Creative Commons Attribution License, which permits unrestricted use, distribution, and reproduction in any medium, provided the original work is properly cited.

\title{
Ryan McWhorter
}

UNICEF, Copenhagen, Denmark

I enjoyed reading the article and see value in the tool. I look forward to using it in the field.

Please see my comments below for the authors' consideration.

\begin{abstract}
:
I think the first sentence's sentiment is borrowed from an oft-cited statement that immunization is one of the most cost-effective interventions for children's health. Instead, this statement says that "Delivery.... is one of the most effective interventions to ensure availability of supplies...". I think it's obvious that the delivery of a product is one of the most effective interventions to having the product available. I don't think I'd call it an intervention, though. Delivery is just part of the operation, not an intervention. I recommend the authors consider a different intro statement regarding the importance of delivery.
\end{abstract}

\section{Introduction:}

The first paragraph focuses on the efficient and optimized distribution. While budgets are a concern for COVID response, I think these opinions deserve a reference. Are governments more concerned with effective distribution or efficient distribution? It could be (and likely is) both, in which case this paragraph would suggest that both areas need to be addressed in the planning and in the tool. I think the paper goes on to support this idea by having both risk and speed in the objective function, but this sentence tends to focus only on efficiency.

The third paragraph warrants a reference for both "one of the most important decisions" and for comments about "no tools", even if this is clarified later in the article, it could reference these points.

The fourth paragraph warrants a reference for impacts of Idai on Mozambique's health supply chain.

\section{Methods:}

Box 1: is there an article/report/survey/feedback to reference for these questions?

Constraints: Is there a need for a constraint on the "driver's day"? For example, that the driver can spend only $\mathrm{X}$ hours on the clock?

For distances, the time factor may be a more relatable quantification than distance, especially if taking into account transit through urban areas and roads that are known to be 
in poor condition.

Usability:

In the comment regarding existing tools in the first paragraph and their usability, suggest a reference for the statement or reference back to Landscape Analysis.

A table or graphic representing the Nielson heuristics and recognition in the tool would be helpful, as the reader cannot keep track of the $1^{\text {st }}, 5^{\text {th }}$, or $6^{\text {th }}$ referenced heuristic.

\section{Computational Performance}

Are the two product categories limited to cold chain and ambient, and is cold chain assumed to be $2-8 \mathrm{C}$ ? This could be better defined in the text for the reader.

This is not my area of expertise, but I imagine that software developers would want to see more data in this section as it pertains to comparisons and the definition of "good results" as it applies to testing against 50 facilities. I listed in my answers above "Partial" on this section because I don't know as much as software developers regarding this section in terms of ability to replicate or analysis.

Is there a reference (report, survey, publication) for the "reasonable number of vehicles"? I would agree with the statement, but I don't have proof.

\section{Use Cases:}

Training: I didn't see answers to all four posed questions? It looks as if only reaction and learning are answered....what about behavior and results?

\section{General Comments}

It would be helpful for the reader to outline the scope of the tool at the top of the article. As I understand, it's for optimizing routing from 1 location to $\mathrm{N}$ locations - so the focus is on the location that manages distribution downstream (as opposed to say, an area that has multiple distribution points or a facility that can both drop-off and pick-up goods).

Recommend to the authors to run the text by a copy editor to clean up grammar and word choice.

Is the rationale for developing the new software tool clearly explained?

Yes

Is the description of the software tool technically sound?

Yes

Are sufficient details of the code, methods and analysis (if applicable) provided to allow replication of the software development and its use by others?

Partly

Is sufficient information provided to allow interpretation of the expected output datasets 
and any results generated using the tool?

Yes

Are the conclusions about the tool and its performance adequately supported by the findings presented in the article?

Partly

Competing Interests: No competing interests were disclosed.

Reviewer Expertise: Global health and immunization supply chain planning

I confirm that I have read this submission and believe that I have an appropriate level of expertise to confirm that it is of an acceptable scientific standard, however I have significant reservations, as outlined above.

Author Response 26 Oct 2021

Mariam Zameer, VillageReach, Seattle, USA

Abstract: This is a good point, and we have modified the introductory sentence.

\section{Introduction:}

We modified the sentence to include efficient and effective, "This is even more critical today with the COVID-19 pandemic, where efficient and effective distribution of the COVID-19 vaccine is needed."

Reference added for "one of the most important decision". Sentence changed about "tools" as the landscape and literature review is summarized in the paper under "Landscaping of existing methods and tool".

Reference added on impact of Idai.

\section{Methods:}

VillageReach is a close supply chain partner with the government in Mozambique, and the questions came from several discussions and meetings with government stakeholders.

Yes, there is a need for a constraint on the length of a "driver's day". This can be reflected in the start time and return time of the parameters sheet (figure 1). A sentence has been added to clarify this.

Yes, the time factor could be more relatable. However, it might change during the time of the day, especially in urban areas. We decided to use distances between facilities and allow for different vehicles with different speeds, so in this way, we do

Usability: consider time but assume it is the same throughout the day.

Thank you for the suggestion. We added a reference back to the section Landscaping of existing methods and tools.

Thank you for the suggestion. A table summarizing the usability heuristics has been added, and language simplified for easier reading.

\section{Computational Performance:}

We only consider two product categories, cold chain and ambient. We do not assume 
a temperature range for the cold chain, or for ambient temperature. When the user identifies the vehicles with cold storage, they can determine an appropriate temperature range. We reworded this in the text as follows, "... aggregating the products into two categories: those requiring cold storage (such as vaccines) and those kept at ambient temperatures. We do not assume a temperature range for the cold chain, or for ambient temperature. When the user identifies the vehicles with cold storage, they can determine an appropriate temperature range that satisfies the health products' requirements (e.g., 2-8 ${ }^{\circ} \mathrm{C}$ for many routine vaccines)."

This was also requested by another reviewer. We expanded the paragraph on computation time and referred to Petroianu et al. for detailed results.

This number came from experience and discussions with stakeholders, and a phrase is added, "Based on our experience and discussions with stakeholders, ..."

Use Cases: Unfortunately, due to the COVID-19 pandemic in 2020, the full deployment of RoOT has been delayed, and we are not able to answer all the questions.

\title{
General Comments:
}

It can be used by any facility distributing products - whether it's one big provincial warehouse or multiple large facilities delivery to smaller facilities. We have added a line to clarify this.

Paper has been copy edited and cleaned for grammar and easier reading.

Competing Interests: No competing interests were disclosed.

Reviewer Report 18 March 2021

https://doi.org/10.21956/gatesopenres.14437.r30463

(C) $2021 \mathrm{Ni} \mathrm{H}$. This is an open access peer review report distributed under the terms of the Creative Commons Attribution License, which permits unrestricted use, distribution, and reproduction in any medium, provided the original work is properly cited.

\author{
Hua Ni \\ 1 USAID GHSC-PSM, Arlington, VA, USA \\ 2 IBM GBS, Falls Church, VA, USA
}

The paper describes the RoOT for distribution of vaccine. This tool addresses a very practice needs of supply chain last mile distribution with dynamic routing capability. I applaud the authors' effort to create an open source solution that factors the operational environment to make the tool more accessible for broader usage in the field of LMIC countries.

Among the questions raised to the reviewer, I answered "Partly" for the following two questions.

1. Are sufficient details of the code, methods and analysis (if applicable) provided to allow replication of the software development and its use by others? 
2. Is sufficient information provided to allow interpretation of the expected output datasets and any results generated using the tool?

Here are some specific comments that I suggest the authors consider, either providing additional details or making some clarifications:

1. Page 4: the comments around existing landscape and in particular on the final two candidates are a bit subjective in the absence of further details. I suggest providing some examples on the complexity, cost, and skills needed to operate.

2. Page 5: if vehicles have fixed ambient and cold capacity, it seems that the constraint of requiring exactly one vehicle to visit each health facility may be too limiting. It is plausible to result in lower vehicle utilization given either ambient or cold storage could become the bottleneck first.

3. Page 5: it is not clear whether the transit time refers to the whole route or just the portion that still has vaccine onboard. If we are to reduce spoilage probability, it seems to be the case that we want to minimize the transit time when vaccine is still onboard the vehicle, and the empty return segment is less critical since no vaccine is onboard, and cost doesn't seem to be part of the stated objectives.

4. Page 5: while the weight used to combine the two objectives is easy to use, it is prone to misuse/misinterpretation. One may think 5 and 5 would put transition time and risk penalty equally important, but without knowing the scale of the individual objective values, the effect is unpredictable. I suggest providing some additional guidance on the nuances here.

5. Page 5: it is not clear as how risk penalty objective is calculated. I suggest providing some clarification.

6. Page 6: it is not clear if the vehicles are of different capacity or have the same capacity and just differ by the risk factor. Suggest providing some clarification.

7. Page 8: while it references the prior page on VeRSA, it may be beneficial to add a high-level recap of the algorithm.

8. Page 9: when a road is blocked due to emergency, it would have cascade of impacts on the OD matrix. I suggest providing some guidance to the users here.

9. Page 12: the screenshot seems to indicate that Non-Refrigerated Utilization of Vehicles at $360 \%$ which seems to be wrong. The Refrigerated Utilization of Vehicle is at $1.8 \%$. Is it out of the total capacity of the vehicle? I suggest updating the tables.

10. Page 13: it may be beneficial to cite some solution quality result from the MZ operation to further strengthen the conclusion of the effectiveness of the tool.

As I indicated, I applaud the authors' effort, and hope my reviews are beneficial to strengthen this already strong paper. All views expressed here are my personal views and don't represent any of my affiliations. 
Is the rationale for developing the new software tool clearly explained?

Yes

Is the description of the software tool technically sound?

Yes

Are sufficient details of the code, methods and analysis (if applicable) provided to allow replication of the software development and its use by others?

Partly

Is sufficient information provided to allow interpretation of the expected output datasets and any results generated using the tool?

Partly

Are the conclusions about the tool and its performance adequately supported by the findings presented in the article?

Yes

Competing Interests: No competing interests were disclosed.

Reviewer Expertise: Not in a research role. Education background in operations research, specializing in mathematical optimization. 5+ years of experience in public health supply chain operational analytics, including last-mile distribution.

I confirm that I have read this submission and believe that I have an appropriate level of expertise to confirm that it is of an acceptable scientific standard, however I have significant reservations, as outlined above.

Author Response 26 Oct 2021

Mariam Zameer, VillageReach, Seattle, USA

1. We added some more details based on practical experience of using the tools: "Also, based on our experience, they require detailed data that is often not readily available in LMICs, such as geographic coordinates or details of road networks. The user interface of the existing tools is complex for those who may not be familiar with it which requires technical assistance that can be costly to some governments"

2. Our model chooses one vehicle at a time to create a route, resulting in that vehicle visiting as many facilities as possible during its route, according to its capacity. Therefore, its utilization would be generally high. If we allow more than one vehicle to visit each center, it would result in higher transit time and lower vehicle utilization.

3. Yes, considering minimizing the transit time only when vaccine is onboard would be an interesting future improvement, whereas the model minimizes the total transit time of all routes (updated in the text). The risk penalty representing vaccine spoilage is considered for each segment of the total route. It is important to keep track of the total transit time, 
including the empty return segment, to ensure the maximum time spent on a route during a single day is respected.

4. That is good feedback that it is prone to misinterpretation. We normalize the objective values so the chosen weights affect them similarly. As suggested, we added an explanation; "The tool normalizes the values of each objective, so the weights affect each objective similarly. For example, weights of 5 and 5 give equal importance to transit time and risk, due to the normalization."

5. Thank you for the suggestion. We added some more details, and "The user classifies the vehicle and road conditions, which the tool converts to a number and uses to calculate risk"

6. We added, "Different types of vehicles may have different risk penalties, as well as different storage capacities."

We have clarified another paragraph later to indicate the user enters the transport capacity for each vehicle: "The user enters the cold and ambient transport capacity for each vehicle, and this is a constraint the model considers when optimizing routes. The user can enter any type of land vehicle and its transport capacity. For example, a motorcycle's cold storage capacity may be the capacity of a small vaccine carrier with some additional space to carry ambient products, like syringes or essential medicines. On the other hand, a refrigerated truck would have a larger transport capacity for cold and ambient products, which the user would input.

7. Thank you for the suggestion. We added, "VeRSA calculates two indices based on the problem constraints to decide which vehicle to use for the route and which center to visit next. Every time that a new center is visited and added to the solution, the index is recalculated to choose the next best center to visit. Therefore, the indices are used to create good and feasible routes in a timely manner."

8. We added some more details in the text and updating the "road_condition" matrix if a road is blocked.

9. Thank you for catching this. You're correct, and we have updated figure 7.

10. We had great feedback from the users, but did not have the opportunity to fully deploy the tool, due to the COVID pandemic. We are looking for opportunities to deploy the tool, and open to collaborations.

Competing Interests: No competing interests were disclosed. 